\title{
The Responsiveness of Tax Yield to Increases in National Income
}

\author{
by \\ Mohammad Zubalr Khan*
}

\section{INTRODUCTION}

Taxes are the most important element responsive to government policy and in effect the major instrument for mobilising the increments in national income for investment or expenditure by the state. However, there are severe administrative and political limitations to the extent to which additional taxation measures, such as the expansion of the base, increasing the rates, or imposing new taxes, can be resorted to for increasing the flow of tax receipts. Hence, to meet the ever expanding expenditure requirements of the public sector, the tax structure must rely on its built-in flexibility. The structure of taxation should be such that an increasing portion of the increments in national income gets automatically channeled into the public exchequer without basic budgetary alterations.

While planning for development accurate estimates need to be made of the resources available in future to meet the growing expenditure of the public sector. These estimates will indicate the need for activising additional means of revenue generation. Thus, it becomes essential to be able to predict what additional revenue is capable of being mobilised within the framework of the existing tax structure as national income increases. A common measure of the responsiveness of the tax system to the increases in national income is the elasticity of the tax system.

This study has been undertaken to calculate, as accurately as possible, the elasticity of the tax structure in Pakistan to extend the revenue projections into the future, and to compare the values obtained with those of the other developing and developed countries.

-The author is a Staff Economist at PIDE. He is grateful to Dr. B.A. Azhar who guided him in this study. He is also grateful to Dr. A.A. Ercelawn and Mr. A.R. Kemal for their suggestions and UBL Computor Centre for computor assistance. However, the author alone is responsible for any errors remaining in the paper. 


\section{DEITITION AND METHODOLOGY}

The response of the tax system to increase in national income can be classified under two broad headings. It is either the result of the built-inflexibility or the bouyancy of the tax structure.

i) The built-in-flexibility refers to the extent to which the tax system gives an increased return with every increase in the national income without any change in either the tax base or the rates of existing taxes, or the imposition of new ones. One measure of such responsiveness is the average relationship between the tax revenues and GDP or between individual taxes and the relevant component of GDP. This can be calculated by the simple statistical method of fitting a straight line to the data on the basis of least squares approach. Thus,

$\mathbf{T}=\mathbf{a}+\mathbf{b Y}+\mathbf{u}$

Where $T$ is tax revenue, $Y$ is GDP, and $u$ is a stochastic component. The slope of the function $d T / d Y=b$, and is therefore the marginal rate of taxation or the "flexibility co-efficient".

A more often used index of the responsiveness of tax yield to GDP is the elasticity of the tax structure, defined as the ratio of the rate of increase in tax yield to that in national income (or a given component of national income in the case of specific taxes).

$$
E_{T}=\frac{d T}{T} \cdot \frac{Y}{d Y}=\frac{d T}{d Y} \cdot \frac{Y}{T}=\frac{d T}{d Y} / \frac{T}{Y}
$$

where $E_{T}$ is the elasticity of tax yield, $T$ is the tax yield and $Y$ is the national income.

As is obvious from equation (2), the elasticity of a tax may be greater, less than or equal to unity, depending on whether the marginal rate of taxation is greater, less than or equal to the tax-GDP ratio.

The elasticity of a tax can be calculated by fitting the data to a loglinear function, of the type

$$
\begin{array}{r}
T=a Y^{b} \ldots \ldots \ldots \\
\log T-\log a+b \log Y . \\
\text { the slope of the function, } b, i \\
\frac{1}{T} \cdot \frac{d T}{d Y}=\frac{b}{Y}
\end{array}
$$

where the slope of the function, $b$, is given by differentiating (4) with respect to $Y$, 


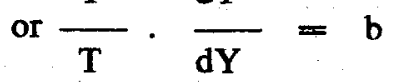

which is by definition the elasticity of the tax with respect to $Y$.

Since built-in flexibility measures the response of the tax yield excluding the effect of fresh taxation proposals, we, therefore, correct the $T$ data. The usual procedure is to add or subtract from the total tax receipt figures, the change in yield due to the new reform only, in the year in which it becomes effective. In the following years, the new rates or base are considered as part of the existing structure and their effect ignored. Obviously this is a great simplification.

Alternatively, when dealing with exogenous changes occuring in functional relationships a usual technique for estimating these relationships is to introduce a dummy variable for each exogenous change. Relevant to our problem of eliminating the effect of a new tax measure from the total tax yield so that a functional relationship with regard to income can be worked out, Singer [10] has suggested that any tax reform be considered as an exogenous factor; and that each should, therefore, be represented by a dummy variable. The latter methodology has been adopted in this analysis.

ii) The other category of increase in tax yield is the result of changes in the rates and structure of the tax system, including the widening and extension of the base, addition to the number of taxes and increases in the rates of taxation. The two categories taken together account for total increases in tax revenue. The bouyancy of the tax system refers to the ratio of the percentage change in total tax revenue, to the percentage change in national income (or the relevant component of national income in the case of specific taxes), where the change in revenue is a sum of the two categories.

\section{COVERAGE, SOURCE, AND DATA}

This study covers the period from 1960-61 to 1971-72. Although figures of the revised estimates of central and provincial tax revenues are available for 1972-73; the corresponding figures for national income and its components are only provisional, making the inclusion of the present year difficult.

Data concerning central tax revenues was supplied by the Central Board of Revenue and show the central taxes collected from West Pakistan only. This will include a source of error because of payment of tax on income earned in East Pakistan by companies having head offices in West Pakistan. For reasons given by Akhlaqur Rehman [8] the margin of error is assumed to be insignificant.

Data concerning provincial tax revenue is reproduced from Finance Ministry's publications. For the years after the break-up of one unit, the provincial revenue is the sum total of the taxes collected by the four provinces of West Pakistan.

The revenue data used has not been corrected for arrears and evasions which are not includ zd in it. Neither have the GDP figures and its components 
been corrected for the amounts not included in the tax base. In the regressions, however, provision has been made to account for these discrepancies.

Figures of GDP and its components are taken at current factor cost because the taxes are levied on the same valuation. National accounts figures are quoted from the C.S.O. publications, and IBRD corrected estimates. To trace the various tax reforms and their estimated effect on the tax yields, the budget speeches and their summaries have been quoted.

\section{FRAMEWORK OF ANALYSIS}

The main difference in the concepts of elasticity and bouyancy of the tax system is that in the former the effects of new reforms are to be eliminated from the tax yield before a functional relationship with national income or its relevant component is calculated, while for calculating bouyancy, no such corrections have to be made.

In the relationship between tax revenues and income, suppose there are two functions which apply, one before and one after a particular reform. Assuming that the coefficient of $Y, b$, is common in both, we can then use all the data and obtain the best fit by using dummy variables (D.V) in an equation of the type:

$$
T=A+b \underset{i=1}{\mathbf{Y}+\sum d_{i} D_{i}}
$$

Otherwise if the intercept is assumed constant and the $b$ term changes, implying that the arrears or ratio of taxable income to personal income remains the same while the elasticity changes, then the form of the equation will be:

$$
T-A+\underset{i=1}{n} \sum_{i=1} D_{i}+u
$$

If there is no constant term an alternative method to the use of D.V., is to run separate regression for the subset periods, in which b's are different. In the case of separate regressions, covariance analysis would be used to test whether the $\mathbf{N}$ number of $\mathbf{b}$ 's are statistically different. Whereas if D.V. are used, the regression results will automatically provide a test of significance for the difference between bs.

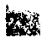
of the type:-

One of the procedures in the second option is the use of an equation

$$
T=A+a_{1} y_{1}+\hat{a}_{2}\left(D_{2} Y_{2}\right)+\ldots \ldots \ldots+\hat{a}_{k}\left(D_{k} Y_{k}\right)
$$

where $\hat{a_{i}}=\left(a_{i}-a_{1}\right)$

This method gives direct estimates of $a_{1}$ and estimates of the difference between $a_{1}$ and $a_{1}$. Suppose $\hat{a}_{i}$ is not significant then a second regression is run with k-1 groups. 
In this paper the elasticity of the tax system has been worked out by fitting the data to a log-linear function of the type:

$$
\log T=A+B \log Y+d_{1} D_{1}+d_{2} D_{2}+\ldots \ldots+d_{n} D_{n}
$$

where $\mathbf{D}$ stands for $\mathbf{n}$ number of dummy variables and $B$ is the elasticity coefficient. The use of the constant needs to be justified on statistical and economic grounds.

\section{(a) Statistical Justification}

Supposing the relationship between tax revenue and income is nonlinear with zero intercept and this is most probable because most relationships in real life are such, then let us analyse the region of the curve relavant to our data in the following diagram.

\section{DIAGRAM 1}

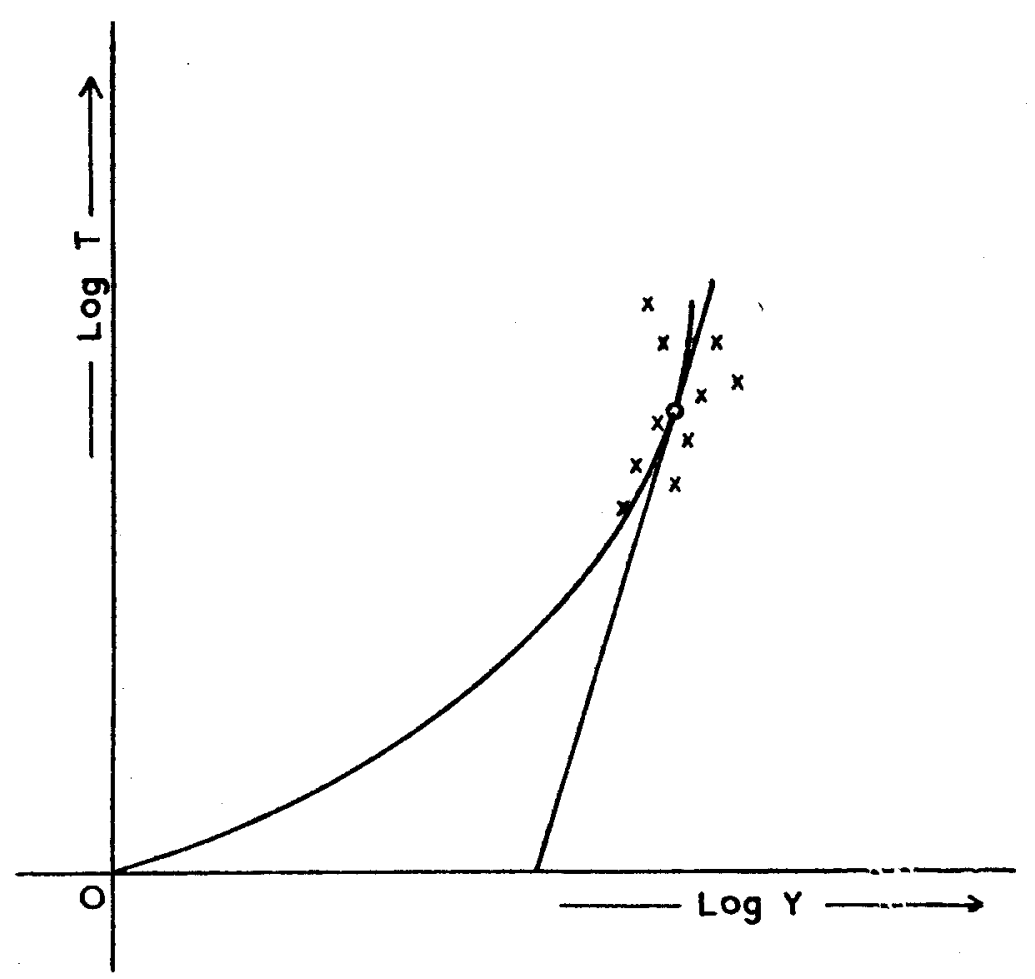

Now when we fit a linear function to the cluster of points we have, it will approximate to a tangent of the curve in that region. Such a straight line will not pass through the origin if the original curvi-linear line, had zero 
intercept. However the sign of the intercept of the fitted straight line is not determined.

(b) Economic Justification

Assuming that the basic tax revenue-income relationship is given by $\log \bar{T}=\mathrm{a} \log \mathrm{Y}+\mathrm{U}$

Where $\mathrm{T}^{*}$ is total tax-revenue expected. Considering that there are arrears and evasions each year, which means that $T$ (revenue actually collected) is say $\mathrm{K}$ times $\dot{\mathrm{T}}$, then we have $\log \mathrm{T}=\log \mathrm{K}+\log \mathrm{T}^{*}$

Hence $\log \mathrm{T}=\log \mathrm{K}+\mathrm{a} \log \mathrm{Y}+\mathrm{u}$

Or we could alternatively justify the use of the constant term by assuming that $\dot{Y}=K$ Y where we assume that taxable income $\mathrm{Y}^{*}$, is $\mathrm{K}$ times personal income $Y$.

$$
\begin{aligned}
& \text { Hence } \mathrm{T}=\left(\dot{\mathrm{Y}}^{\mathrm{a}}=(\mathrm{KY})^{\mathrm{a}}\right. \\
& \text { or } \log \mathrm{T}=\mathrm{a} \log \mathrm{K}+\mathrm{a} \log \mathrm{Y}+\mathrm{u}
\end{aligned}
$$

In equation (5)

$$
\log T=A+b \log Y+\sum_{i=1}^{n} d_{i} D_{i}
$$

the constant term shows that there is a difference between taxable and personal income. And since the latter is always larger than the taxable income we would expect a negative intercept.

According to the methodology, one dummy variable should be introduced for each change in the tax rate or base. But since the changes have been so numerous over the period of analysis, we have introduced a dummy variable for those reforms only, whose effect on the tax yield is relatively greater. A still further simplification has been necessitated. When working out a regression concerning total tax revenues, a dummy variable was introduced only when the gross effect of the entire tax reform in that year was relatively great. For the regressions concerning the separate taxes, a dummy variable was introduced for particular reforms and not the overall changes in that tax str cture. A list of the reforms represented by dummy variables is give in Table III.

The marginal rate of taxation or the "flexibility co-efficient" has b en calculated by fitting the data to a linear function of the type

$$
T=a+b / y+d_{2} D_{1}+\ldots \ldots \ldots \ldots+d_{n} D_{n}
$$

Here $b^{\prime}$ is the marginal rate or "flexibility co-efficient".

However, when calculating the bouyancy of the tax structure, a loglinear function is used again, but without the dummy variables because the effect of new reforms has to be ignored. 
$\log \mathrm{T}=\mathrm{A}+\mathrm{B}^{\prime} \log \mathrm{Y}$

Here $B^{\prime}$ is buoyancy of the tax.

\section{RESULTS}

A number of regressions were worked out for pairs of variables, whose correlation may have economic significance, at least theoretically. The results are summarized in Tables I and II. Computations were done at the UBL Computor Centre, Karachi on their computer using programme GREG 3.

As alternative measures of goodness of fit, the values of $R^{2}$ (multiple correlation) and $t$-statistics are also shown. The $t-$ ratios provide a measure of significance of the regression co-efficient. Also given are the F-statistic and Durbin-Watson Statistics, the latter provides a measure of the auto-correlation of the residuals. In the table, an asterisk appears where the different tests given insignificant values according to their hypotheses. It is clear at first glance that almost all results are statistically reliable.

\section{(1) Elasticity Results}

The following table shows the elasticity of the various taxes against GDP and the relevant component of GDP for the period 1960-61 - 1971-72.

Regression variables

1. Total Tax Revenue/GDP

2. Central Tax/GDP

3. Direct Tax/GDP

4. Indirect $\operatorname{Tax} / \mathrm{GDP}$

5. Income Tax/Non-Agri. Income

6. Excise/GDP

7. Excise/MFG

8. Sales Tax/W.R. Trade

9. Customs Duty/Imports

10. Income Tax/MFG
Elasticity

1.35

1.47

0.87

1.57

1.02

2.28

1.71

0.98

0.77

0.89

The income elasticity of the total tax revenue is relatively high compared to the other figures in the table. This is explained by the fact that excise duty whose income elasticity is 2.28 (still higher) accounts for $36 \%$ of all tax revenues. In order to increase the elasticity of the tax structure either the share of excise in total revenue must rise, or the income-elasticity of income tax and the response of custom duty to increases in imports must rise. In the later alternative, the scope for improving the elasticity is better with income-tax than with custom duty for two reasons. Firstly, the response of income-tax to increases in manufacturing sector's income is poor, chiefly due to the numerous tax holidays enjoyed in that sector, hence having great scope for improvement. And secondly, manipulation with custom duty requires greater caution because import duties have an effect other than just revenue collection. 
An anamoly is observed in the comparison of income-elasticities of direct and indirect taxes. Direct taxes which are based on income are less correlated to income than indirect taxes. This is still true even if only income tax is compared with the indirect taxes.

Among the indirect taxes, sales tax has shown a low elasticity. This could be due to the merger of sales tax with excise, or because there are too many exemptions. Yet another reason mav be that since sales tax is levied at the production and import stages where rise in prices are not fully reflected; sales tax does not respond fully to. price increases. The elasticity of sales tax can be increased by taxing at appropriately higher rates those commodities for which the marginal propensity to consume is greater than the average propensity. This, however, might not be compatible with the government policy. Customs duty is another indirect tax with a low elasticity. This is because of differential rates on the various imports when the composition of imports is heavily weighted by foodgrains and fertilizers, which carry no duty, by raw materials which carry low duties and because of decreasing imports of consumer goods which carry relatively higher rates of duties.

A point of interest is that the income elasticity of excise is higher than the elasticity of the same tax with regard to the relevant component of GDP i.e. the manufacturing sector's income. This is explained by the higher growth rate in the latter sector than the growth rate of GDP.

The income-elasticity of central taxes is higher than the elasticity of the entire tax structure implying that the provincial taxes, where agricultural taxes constitute a major component, have a dampening effect on the overall elasticity.

(2) Buoyancy Results

The buoyancy figures for the various taxes are given below:

Regression variables

1. Total Tax Revenue/GDP

2. Total Central Taxes/GDP

3. Provincial Taxes;GDP

4. Direct Taxes/GDP

5. Indirect Taxes/GDP

6. Excise/GDP

7. Customs/Imports

8. Sales Tax/W.R. Trade

9. Income Tax/Non-Agri. Income

10. Land Revenue/Agri. Income
Buoyancy

1.20

1.29

0.62

0.79

1.36

2.18

1.69

0.28

1.04

0.13

The buoyancy figures of all taxes except income tax and custom duty are lower than the corresponding elasticity figures. This is an astonishing fact since it implies that the tax reforms have only dampened the responsiveness of the tax system. This is explained later. However, the difference in values of buoyancy and elasticity is explained by the use of dummy variables 
when calculating the latter. Only some of the dummy variables had coefficients statistically significant. This means that only some of the tax reforms have had an appreciable effect on the buoyancy, the others were either minor, or so recent that their effect has not yet come out fully.

The dummy variables with significant co-efficients are given in Table I.

\section{(3) Marginal Rate of Taxation}

The marginal rate or the flexibility co-efficient of all taxes was calculated with and without accounting for the discretionary reforms by introducing dummy variables in the former case. The results are summarised below:

Variables \begin{tabular}{c|c} 
Marginal rate & Marginal rate \\
(without discre- & (with discretion- \\
tionary change) & ary change)
\end{tabular}

1. Total Tax Revenue/GDP

2. Central Tax/GDP

3. Provincial Tax/GDP

4. Excise/GDP

5. Excise/MFG

6. Custom/Import

7. Direct Taxes/GDP

8. Indirect Taxes/GDP

9. Sales Tax/W.R. Trade

10. Income Tax/Non-Agri. Income

$\begin{array}{rr}12.5 \% & 12.9 \% \\ 12.8 \% & 12.9 \% \\ - & 0.9 \% \\ 4.8 \% & 6.6 \% \\ 26.0 \% & 36.6 \% \\ 14.6 \% & 47.1 \% \\ 3.9 \% & 3.0 \% \\ 10.5 \% & 10.4 \% \\ 12.5 \% & 2.6 \% \\ 3.5 \% & 3.7 \% \\ & \end{array}$

The results suggest that except in the case of sales tax and direct taxes the discretionary changes have increased the marginal rate of taxation. The flexibility co-efficient for the entire tax structure is only $12.5 \%$, which is not commensurate with a high growth rate of revenue, because a low marginal tax rate is likely to keep the elasticity of the tax system low according to equation 2 . In the case of individual taxes, it is noted that high flexibility co-efficients are associated with higher elasticity.

As pointed out by Akhlaqur Rehman [8], the low flexibility co-efficient of income tax may be mainly due to restricted base; the exemption limit is sixteen times the per capita income and exclusion of the agricultural income has made the expansion of the base very difficult in Pakistan. To make it worse, deductions and concessions contributed to further erosion. The middle-class group earning between Rs. 300 and Rs. 500 per month is likely to grow which means a greater proportion of people will be exempted from paying this tax. According to Akhlaqur Rehman the very high statutory marginal rates of personal and corporation taxes contribute more to evasion of tax payment and less to reduction of income inequality. 
The flexibility co-efficient of sales $\operatorname{tax}$ is $12.5 \%$, higher than the figure obtained without dummy variables. This low figure is again a result of base erosion. A large number of items are excluded while the tax on the other major ones is merged with customs or excise.

The marginal tax rate of land revenue is 0.002 , an exceedingly low figure, because it is a flat rate and shows no progression.

\section{CONCLUSIONS}

The chief conclusion of this analysis is that with the exception of excise duty, the responsiveness of tax yield of the total tax structure, and the individual taxes, to the increase in national income is not high. What is more marked is the relative lack of response of tax yield to taxes based on income, compared with the indirect taxes. Moreover, it is observed that the various tax reforms over the period covered by this analysis, have adversely affected the elasticity of the tax structure. The inelasticity of income tax may be the result of one or more of the many factors.

The slab structure and rate schedule may be defective. As already pointed out the exemption limit in Pakistan is sixteen times the average per capita income and compared with some other underdeveloped countries is the highest among them, including India, Ceylon etc. However, the large proportion of self-employed and the large non-monetised sector make it administratively difficult to collect income tax in lower brackets. Here the only alternative is to reach these pockets through increased sales and excise taxes. However, the scope for improving the structure lies in raising the rates on the middleincome group. Although at levels of income 50 times per capita income, i.e. Rs. 30,000, the Taxation Commission recommends only $30 \%$ income tax, in Britain a tax payer at comparable level of income pays $65 \%$ of his income as tax.

Another reason for the inelasticity of income tax could be that there has been a redistribution of income. A progressive rate schedule can bring in increasing yields only if the tax payers keep on shifting to upper income brackets as income expands. If the redistribution of income is in favour of the low income brackets within the tax payers or in favour of the non-tax payers, the tax yields may not increase in step with the progressivity of the rate schedule. This reasoning, however, assumes that tax evasion or avoidance has spread over all the tax ranges in proportion to their respective incomes.

Administrative inefficiency, corruption, tax avoidance and evasion simply add to the basic reasons for the lack of response of tax yields to growing income.

Compared with values of elasticities of the tax structures of other countries, Pakistan has to go a long way to compare with Indian tax elasticity of 2.40. Income tax in Pakistan is less elastic than in most of the listed countries.

A crucial point to note is the higher value of the elasticity of the taxes compared to the buoyancy figures. This implies that the various tax reforms have contributed towards lowering the responsiveness of the tax structure to increases in income. In absolute value, the returns from the taxes will be greater after the reforms, but the rate of increase in the tax yield attributable 
to the reform only, will be less than the rate of increase of the tax yield attributable to the existing structure. In other words, the elasticity of the new taxes is less than the elasticity of the older taxes. This is a direct implication of the results but not a separate exercise.

This is a disturbing result but it has been mathematically confirmed by the figures obtained for the other variables in the analysis. In the regression worked out for the elasticity of the entire tax structure, all four dummy variables have negative co-efficients. Hence we have

$$
\mathrm{T}=-2.8+1.35 \mathrm{Y}-1.64 \mathrm{D}_{1}-1.69 \mathrm{D}_{\mathrm{z}}-17.3 \mathrm{D}_{\mathrm{z}}-2.6 \mathrm{D}_{\mathrm{a}} \ldots . . \text { (i) }
$$

while for buoyancy we have:

$$
T=-2.0+
$$

From the two equations, it is clear that the co-efficients of $\mathrm{Y}$ in equation (i) should be higher than in equation (ii), since it has to compensate for the four negative terms and a lower constant term, with the values of $T$ and $Y$ the same in both equations.

In order to analyse the reasons for the lowering of responsiveness of the tax structure, more regressions were worked out using the data of the first 11 years of the period under consideration, then the first 10 years and so on for the shortest period of the first 7 years. This would indicate the trend in the value of buoyancy over the years when the major reforms were brought about. It is not surprising that a constant downward trend in the buoyancy value is observed as the number of years is increased. Till 1966-67, the buoyancy of entire tax structure was 1.31. But by the next year it was only 1.21, a marked decline. This may be attributed to the reforms of 1966-67 which included the imposition of refundable surcharge on income tax and a super tax of $10 \%$, excise on petroleum products, cement, cotton yarn etc., merger of sales tax on cement, soda-ash etc., with excise and custom duty, and the tariff rationalization. All these and other minor reforms did yield an additional Rs. 3715 lacs in revenue, but the rate at which this yield from the above mentioned reforms, increased, was far lower than that for the existing structure. Similarly other reforms can be pinpointed for the further lowering of the buoyancy figure. In the case of the elasticities of separate taxes, we observe the same phenomenon, except in the case of income tax and customs duty.

The major implication of the existence of this phenomenon, is that in order to obtain increasing yields of tax receipts (as a proportion of national income) the government will have to go on imposing new taxes unless the yields from the new taxes are responsive to increases in income. 


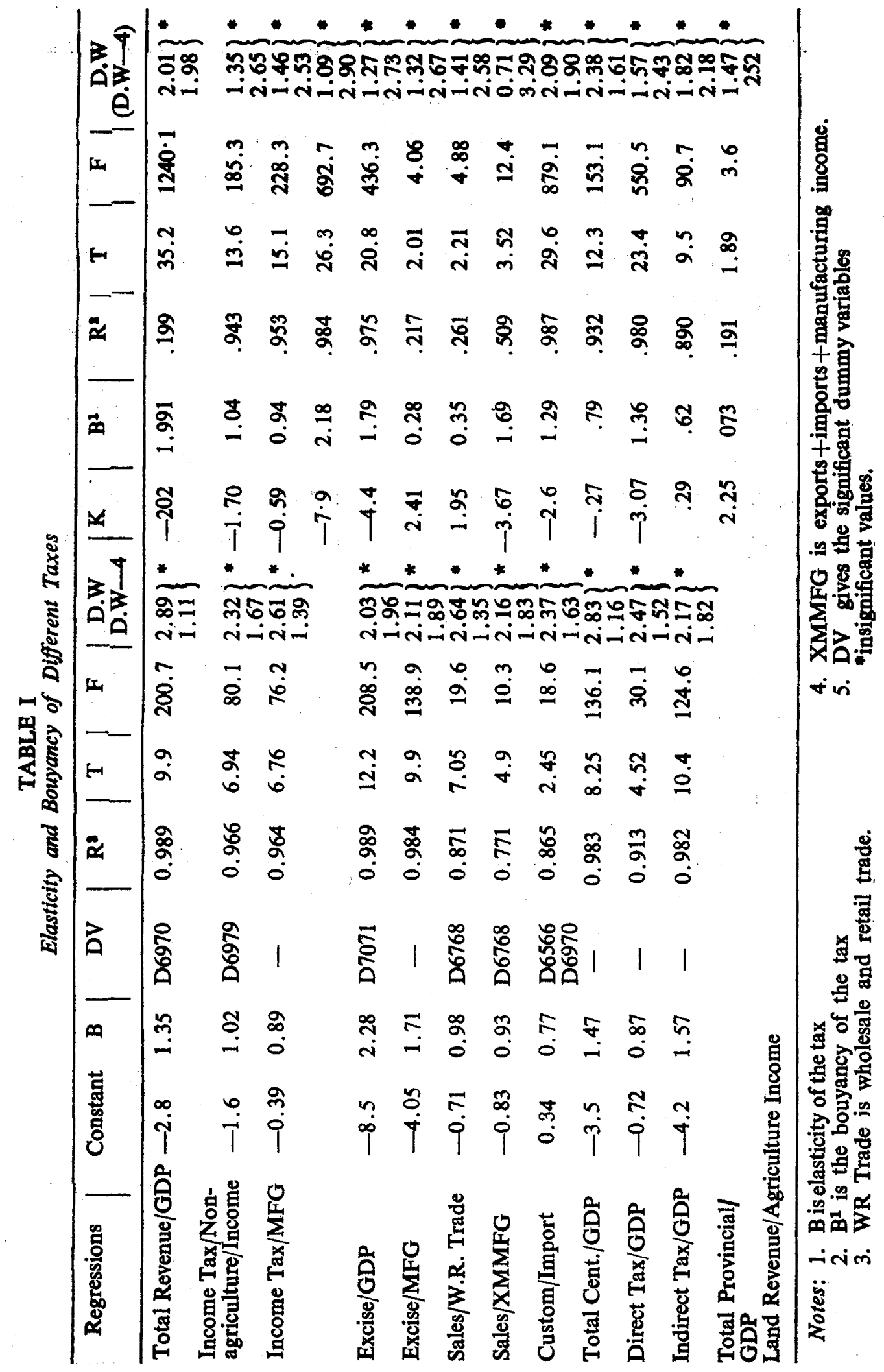


TABLE II

Marginal Tax Rate or Flexibility Coefficient

\section{Regression}

1. Total Revenue/GDP

0.129

0.965

0.125

0.956

2. Income Tax/Non-agri. Income

3. Income $\operatorname{Tax} / \mathrm{MFG}$

4. Excise/GDP

5. Excise/MFG

6. Sales/SR. Trade

7. Sales/XMMFG

8. Custom/Import

9. Total Cent/GDP

10. Direct Tax/GDP

11. Indirect Tax/GDP

12. Provincial Tax/GDP

13. Land Revenue/Agriculture Income
0.037

0.913

0.035

0.942

0.135

0.915

0.123

0.921

0.066

0.987

0.048

0.998

0.366

0.983

0.260

0.995

0.026

0.103

0.125

0.777

0.016

0.132

0.059

0.700

0.471

0.432

0.146

0.851

0.129

0.987

0.128

0.983

0.030

0.934

0.039

0.926

0.104

0.979

0.105

0.957
$0.009 \quad 0.828$

0.002

0.308

Notes: $1 . \mathrm{b}^{\prime}$ is the marginal tax rate with discretionary changes.

2. $b^{*}$ is the marginal tax rate without discretionary changes. 
TABLE III

Reforms Represented by Dummy Variables

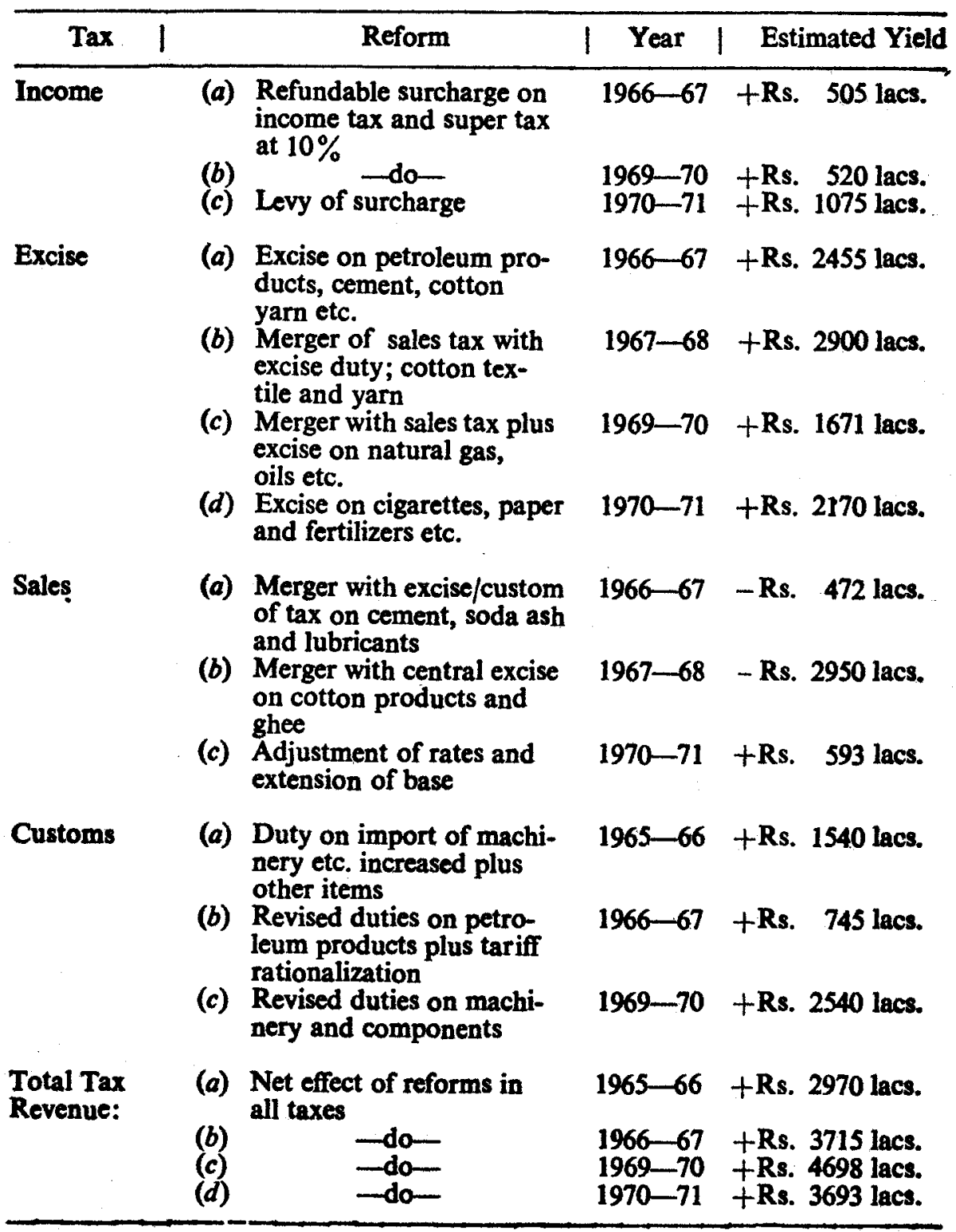




\section{TABLB IV}

Share of Important Taxes in Total Fax Revenue

(Figures in percenthges)

\begin{tabular}{llllllll}
\hline Year & Central & | Direct & | Income & Seles & Curstoms & Excise \\
\hline $1960 / 61$ & 84 & 36.0 & 19.02 & 21.9 & 25.3 & 17.4 \\
$1961 / 62$ & 85 & 35.5 & 20.2 & 20.2 & 28.1 & 15.8 \\
$1962 / 63$ & 86 & 36.0 & 20.3 & 18.9 & 25.7 & 18.3 \\
$1963 / 64$ & 85 & 37.0 & 19.7 & 20.8 & 20.4 & 23.7 \\
$1964 / 65$ & 88 & 35.0 & 18.8 & 18.7 & 25.8 & 23.2 \\
$1965 / 66$ & 87 & 32.0 & 18.2 & 19.6 & 22.4 & 25.1 \\
$1966 / 67$ & 88 & 33.0 & 15.8 & 19.0 & 21.3 & 31.2 \\
$1967 / 68$ & 87 & 30.0 & 16.8 & 10.7 & 20.9 & 37.1 \\
$1968 / 69$ & 88 & 31.0 & 16.1 & 11.0 & 25.6 & 33.9 \\
$1969 / 70$ & 88 & 30.0 & 17.9 & 10.0 & 23.6 & 36.1 \\
$1970 / 71$ & 89 & 30.0 & 16.5 & 11.0 & 26.0 & 35.5 \\
$1971 / 72$ & 90 & 31.0 & 20.0 & 9 & 24.0 & 36 \\
\hline
\end{tabular}

Source: CBR.

TABLE V

Ratio of Tax Revenue to GDP/Component

\begin{tabular}{|c|c|c|c|}
\hline Total Revenue/GDP & 0.120 & Custopilaport & 0.430 \\
\hline Income Tax/Non-agri. Income & 0.039 & Centrat Tax/ODP & 0.011 \\
\hline Inoome Tax/MFG & 0.159 & Ptor Tax/GbP & 0.013 \\
\hline Excise/GDP & 0.043 & Land Revenue/Agri. & 0.008 \\
\hline Excise/MFG : & 0.0281 & Direct Tax/GDP & 0.037 \\
\hline Sales Tax/W.R. Trade & 0.071 & Indirect Tax/GDP & 0.081 \\
\hline Salos Tax/XMM & 0.037 & & \\
\hline
\end{tabular}




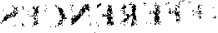 \\ TABLE VI}

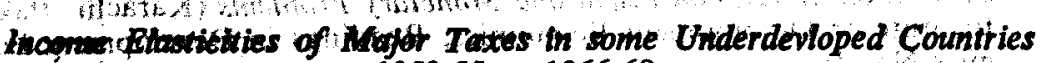
1953-55 to 1966-68

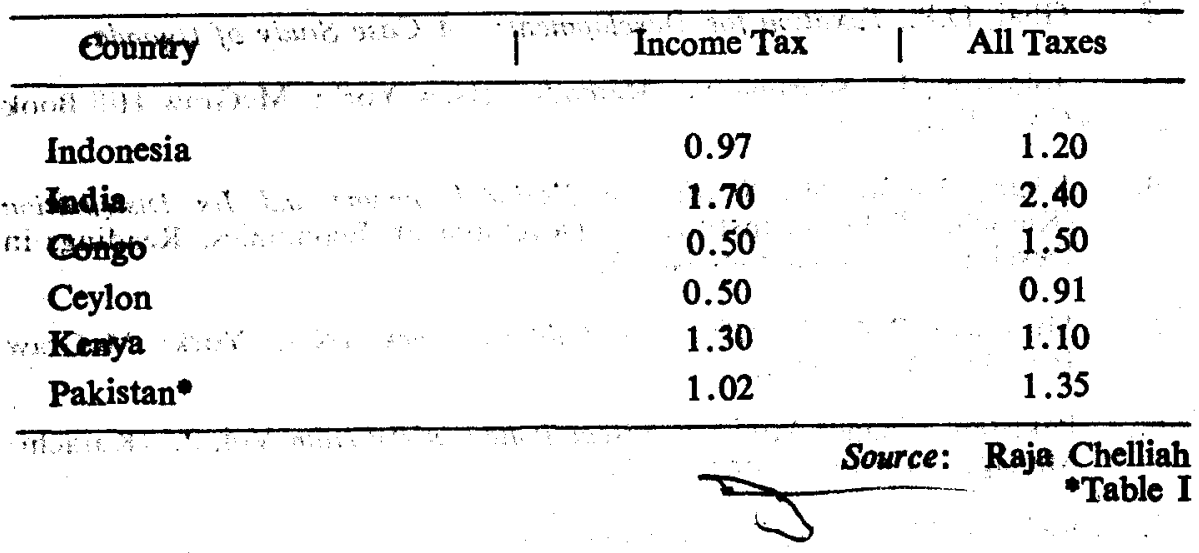

TABLE VII

Trend in Bouyancy. Values of Total Revenue Against GDP over the Last Six Years No. of years

$$
\text { Period }
$$

Regression

co-efficient

1.313

0.99

7

8

9

10

11

12
$1960-61$ to

1966-67

$1960-61$ to

1967-68

$1960-61$ to

1968-69

$1960-61$ to

1969-70

$1960-61$ to

1970-71

$1960-61$ to

$1971-72$
1.214

0.98

1.228

0.99

1.231

0.99

1.223

0.99

1.199

0.99 


\section{REFERENCES}

1. Bose, S.R., Studies on Fiscal and Monetary Problems (Karachi: Pakistan Institute of Development Economics, Readings in Development Economics No. 4).

2. Ghai, D.P., Taxation for Development: A Case Study of Uganda.

3. Johnston, J., Econometric Methods. (New York: McGraw Hill Book Co. 1972).

4. Khan, Taufiq M., Studies on National Income and Its Distribution (Karachi: Pakistan Institute of Development Economics, Readings in
Development Economics No. 5).

5. Musgrave, R.A., The Theory of Public Finance, (New York: McGraw Hill Book Co., 1959).

6. Pakistan, Finance Ministry, Fiscal Policy in Pakistan Vol. 2. (Karachi: Manager of Publications, 1971).

7. Rao and Miller, Applied Econometrics.

8. Rahman, M.A., The Structure of Taxation in Pakistan. (Karachi: United Bank Limited, Research Monograph No. 4).

9. Sahota, Indian Tax Structure and Economic Development.

10. Singer, N.M. "The Use of Dummy Variables in Estimating the Income Elasticity of State Income Tax Revenues", National Tax Journal, June 1968, Vol. XXI, No. 2. 